\title{
Research on College Students' English Learning Burnout
}

\author{
Jingzhi Zhang \\ Xi'an International University, Xi'an, 710077, China
}

Keywords: College English; learning burnout; emotions

\begin{abstract}
In recent years, there have been a problem of a lack of English learning power among college students for a long time, that is, learning burnout, which affects the learning effects to a great extent. This phenomenon is closely related with obscure learning motivation, a reflection of negative learning psychology and it receives more and more attention from the domestic and foreign fields of education and psychology. This paper carries out analysis of the present situation of English learning burnout among college students, explores how to carry out organizational intervention and personal intervention of the pseudo burnout of College English learning with positive psychology so as to improve college students' English learning engagement and effectively lower the degree of their English learning burnout.
\end{abstract}

\section{The Definition of Learning Burnout}

The definition of learning burnout comes basically from the research on job burnout. Pines (1980) and Meier (1985) define learning burnout in this way: learning burnout is a phenomenon that students drain their energy due to long-term study pressure and course load, gradually lose their passion for homework and activities, show indifference and alienation to their classmates and keep a negative attitude towards study. The Taiwanese researcher Yang Huizhen (1998) considers "learning burnout refers to a phenomenon that students show emotional exhaustion, a lack of humanization and diminished personal accomplishment in study due to study pressure and course load or other personal psychological factors".

\section{Causes of Learning Burnout}

\subsection{Learned Helplessness}

Through long-term observation of students and interviews with them, it is discovered that students' English language learning burnout is not caused by long-term “energy exhaustion”, but by their failure in making full use of their free time, learning English negatively and a lack of interest in English, pseudo. In College English learning, students don't have physical exhaustion, a lack of energy, long-term fatigue and weakness while the students show a high degree of learning burnout always cannot face the pressure from English courses and their helplessness and hopelessness are only negative emotions aiming to adapt to College English learning, following after which is their procrastination and further psychological burnout, which of course is caused by their long-term study and a lack of energy, one of the reflections of "learned helplessness". More input with less 
output is one of the characteristics of learning burnout while the students of pseudo learning burnout always invest less and they are more inclined to attribute their failure to a lack of a talent for learning, a lack of interest in learning rather than emotional exhaustion caused by high course load. They can hardly do a good job of trilogy of preview, learning and review and most of them fail to have preview and review, learning passively with a lack of abilities of self-control. In fact, learning burnout is the difficulties in students' adapting to their learning. The learning content, learning methods of College English and teachers' teaching methods are all different those in senior high schools, and the difficulties in College English learning are increased greatly. College English learning has higher requirements for listening, reading and writing at the same time; in addition, there is a larger amount of teaching information of College English given in limited class hours and the course progress of College English is also faster, and students are required to learn automatically with high-efficiency; the learning of College English is students oriented where teachers only play a guiding role while some students are poor in learning autonomy and they overly rely on their teachers' supervision and control, low in the ability of self-control, and accordingly they show low in their learning efficiency. Therefore, they will certainly have difficulties in adapting to their learning of College English, which further causes them to devote less to it, not listen intently and play cell phones in class, not hand in their homework on time, or copy others' homework or even refuse to hand it. Of course, there are also "low-quality diligent students" who appears to be listening intently in class and write what their teachers write on the blackboard, but they fail to have review of what they have learned with only new knowledge in brain forever. They are dull, not flexible and they cannot draw inferences, just like the moneys who break off corn cobs, which exhausts their passion for English learning over time and finally produces learning burnout in them.

\subsection{Gender Difference}

In term of learning burnout of College English, there are obvious differences in gender. The learning burnout is scored from two dimensions: emotions and behaviors and it is discovered that the total grade of the male is higher than that of the female while from the dimension of sense of accomplishment, the total grade of the male is lower than that of the female, which may be caused by the differences in gender. Wen Qiufang (1996) carries out an investigation on English language learning and considers that for English language learners, the time spent on English learning should not be less than five hours per week and only by doing that can they have excellent effects. In addition, the male is more inclines to be impetuous, poor in self-control and it is hard for them to maintain their passion for English learning for a long time; meanwhile, the male are lazier, attracted by the outside world more easily, for example, computer games and accordingly they are more inclined to misbehave.

\subsection{Unclear Motivation of English Learning}

College students are unclear about the motivation of English language learning and further lack power in English language learning. Most students learn English aiming to obtain a good total score and make preparations for the employment in the future, rather than due to their love of English language and culture, thirst for increasing their knowledge of English, that is, the surface motivation of English language learning taking the dominant role rather than the deep motivation. However, the students who learn English language simulated by the surface motivation can only maintain for a short time and they can not keep studying hard of English language all along. The surface motivation of English language learning can not provide students regular and long-term learning activities and once students achieve their short-term goals, for example, passing their final 
examination, they will probably not continue their English language learning and participate in the College English Test Band Four and Six continuously; instead, they will give up studying English in their later time, abrupt in learning, which goes against the rules of language learning.

When students have unclear or weak learning motivation, they will also produce learning burnout, and there are even many students who consider English is less closely related with their major and future employment and they further learn English language only for passing the final examinations, credit and graduation certificate by ignoring the practical values of English language learning. Therefore, they carry out rote English language learning blindly and naturally show lower learning initiative, learning English language more passively. The incorrect cognition of English language learning leads them to fail to set a long-term goal and be unwilling to devote more time and energy to English language learning and pay more attention to the study of specialized courses instead.

\section{Countermeasures of Learning Burnout of English Language}

In the class of College English, it is necessary for teachers to cultivate students' cognitive styles of English language learning, guide them to the correct attribution and look at their own success and failure reasonably. On the contrary, in the class of College English, a lack of positive experiences will lead the student individuals to lose their confidence and further consider it is no use making efforts. Over time, they will easily produce learned helplessness and pseudo learning burnout while it is available to effectively eliminate the negative experiences in the class to carry out organizational intervention and classroom intervention of pseudo learning burnout with positive psychology so as to prevent the pseudo learning burnout from further transforming into real learning burnout. Seen from the above, it is unavailable for teachers to show indifference towards students' emotional requirements and development in the class of College English and positive psychological experiences in the class of College English will arouse students' intrinsic learning interest to a greater extent instead. Students' experience of success and being respected in the process of learning will help eliminate the learning burnout more effectively. In addition, it is also helpful to exercise students' critical thinking and build a positive value system, simulate students' learning motivation of English language learning to carry out positive psychological intervention so as to provide them a lifelong benefit.

It is necessary to combine with positive psychology with good society, positive communities and organizations so as to produce positive influences on human. Social relation, cultural norms and family background are the three which all play a significant important role in the psychological development of a person. Therefore, it is available to carry out intervention of students' learning burnout of College English from three aspects of positive psychology: studying students' personal characteristics, integrating love based ability training into the classroom teaching and providing the guidance in interpersonal skills so as to improve students in their positive subjective experience and happiness in the class with satisfaction with the past and optimism with the future, and improve their sensibility of beauty.

\subsection{Organizational Intervention}

After the entrance of the college freshmen, before the setting of new goals, they always feel a lack of aims and behave blindly, short of power in learning. Therefore, it is necessary for universities and colleges to strengthen their guidance on students' career planning, lead students to get a full understanding of themselves so as to make them set a goal by according to their own interest and characteristics and coming with the social requirements and career direction. In addition, it is necessary for universities and colleges to invite the enterprises or resources managers relevant 
with job orientation to give students an explanation of the requirements of English level and provide them more chances of language practices so as to simulate them to learn English language with practices.

\subsection{Team Intervention}

It is available for teachers to establish a discussion group of English and QQ groups for their students through the network platform to supervise students' study of English language. It is necessary for teachers to be equipped with the basic knowledge of positive psychology, help students make clear of their learning goals and lead them to complete their learning tasks in a planned way. In addition, it is also necessary for teachers to provide more encouragement and humanistic care to the students who fail to take an active part in activities, divide them into groups and arrange them extracurricular learning tasks in a reasonable amount rather than in excess. Meanwhile, teachers should also increase the interestingness of the classroom teaching of English so as to improve students' learning efficiency and engagement. Teachers should guide students to arrange their time for English learning and report to them English studies on time, carry out team interaction activities in the class of College English which can arouse students' learning interest but should be not so boring or formalized. It is necessary for teachers to carry out specific personal intervention of the individuals who engage less in English language learning, provide them control, sustainable supervision and guidance in the process of their achievement of the concrete English learning goals and implementation of English learning plans.

\subsection{Classroom Intervention}

College English class carries out transition from simple teaching to exploration and also pays attention to cultivate students' critical consciousness. It encourages students to carry out cultural exploration and judgement, and rational "questioning" and "reflection" by being not restricted to the book knowledge of "certainty". The classroom discussion of English should be carried out in a planned way and it is unavailable for teachers to impose the current opinions on students and they should provide students proper helps when stating an opinion instead so as to enable students to analyze and comment it and be enlightened after the basic expression and become critical thinkers and learners. Only by doing that can students' enthusiasm and passion in the class be increased and anxiety and tension be reduced as much as possible. Teachers are not only the assigners of classroom tasks, but also they should participate in different links of classroom tasks more. In addition, it is also necessary for them to adjust their expectation on students, teach students with positive attitudes and infect students in the class. Meanwhile, it is necessary for them encourage and guide students to ask them for help on time so as to obtain good teaching feedback and provide students a sense of worth and pride.

\section{Conclusion}

Seen from the above mentioned, it can be concluded that learning burnout comes down to students' emotional problems, so it is necessary for teachers to pay attention to emotional education of students. Only by doing that can students be helped in solving the emotional problems they meet in the process of learning English language from the inside out radically and further setting learning goals and achieving them respectively step by step. 


\section{References}

[1] Li Yongxin, Tan Yamei. Preliminary Study of College Students' Learning Burnout [J].China Journal of Health Psychology, 2007, 15(8): 730-732.

[2] Lian Rong, Yang Lijuan, Wu Lanhua. The Situation of the Speciality Commitment and Learning Burnout of College Students and Their Relationships [J].Psychological Science, 2006, (1>: 47-51.

[3] Zhang Linhua. Investigation and Analysis of the Factors Affecting the Motivation of Students' English Learning[J].Journal of Nanchang College, 2000, (03): 41-51.

[4] Wen Qiufang. The Change Rules and Characteristics of the Motivation, Concept and Strategies of English Learners [J]. Foreign Language Teaching and Research, 2001, 33 (2): 105-110

[5] Wang Xueqin. Discussion on Characteristics and Influencing Factors of College Students' Learning Burnout [J]. Journal of Liaoning Institute of Science and Technology, 2010, 01. 